\title{
Regulation of hepatocyte growth factor-mediated urokinase plasminogen activator secretion by MEK/ERK activation in human stomach cancer cell lines
}

\author{
Kyung Hee Lee ${ }^{1}$, Eun Young Choi ${ }^{1}$, \\ Min Kyoung Kim¹, Myung Soo Hyun', \\ Byung lk Jang ${ }^{2}$, Tae Nyeun $\mathrm{Kim}^{2}$, \\ Sang Woon $\mathrm{Kim}^{3}$, Sun Kyo Song ${ }^{3}$, \\ Jung Hye $\mathrm{Kim}^{4}$ and Jae-Ryong $\mathrm{Kim}^{4,5,6}$ \\ ${ }^{1}$ Department of Hemato-Oncology \\ ${ }^{2}$ Department of Gastroenterology \\ ${ }^{3}$ Department of General Surgery \\ ${ }^{4}$ Department of Biochemistry and Molecular Biology \\ ${ }^{5}$ Aging-associated Vascular Disease Research Center \\ College of Medicine, Yeungnam University \\ Daegu 705-717, Korea \\ ${ }^{6}$ Corresponding author: Tel, 82-53-620-4342; \\ Fax, 82-53-654-6651; E-mail, kimir@med.yu.ac.kr
}

Accepted 8 December 2005

Abbreviations: ERK, extracellular signal-regulated kinase; HGF, hepatocyte growth factor; MAPK, mitogen activated protein kinase; MEK1, MAPK/ERK kinase 1; uPA, urokinase plasminogen activator

\begin{abstract}
The regulatory mechanisms for the proliferation and the particular invasive phenotypes of stomach can cers are not still fully understood. Up-regulations of hepatocytes growth factor (HGF), its receptor (cMet), and urokinase-type plasminogen activator (UPA) are correlated with the development and metastasis of cancers. In order to investigate roles of HGF/C-Met signaling in tumor progression and metastasis in stomach cancers, we determined effects of a specific MEK1 inhibitor (PD098059) and a p38 kinase inhibitor (SB203580) on HGF-mediated cell proliferation and UPA expression in stomach cancer cell lines (NUGC-3 and MKN-28). HGF treatment induced the phosphorylations of ERK and p38 kinase in time- and dose- dependent manners. Pre-treatment with PD098059 reduced HGF- mediated cell proliferation and UPA secretion. In contrast, SB203580 pre-treatment enhanced cell proliferation and UPA secretion due to induction of ERK phos phorylation. Stable expression of dominant negative-MEK1 in NUGC-3 cells showed a decrease in
\end{abstract}

HGF-mediated uPA secretion. These results suggest that interaction of a MEK/ERK and a p38 kinase might play an important role in proliferation and invasiveness of stomach cancer cells.

Keywords: hepatocyte growth factor; mitogen-activated protein kinases; neoplasm metastasis; urinary plasminogen activator

\section{Introduction}

Gastric cancer still remains the leading cause of cancer death in Korea because of the rapidly invasive and metastatic progression of the cancer cells. However, the mechanism for the procession of gastric cancer is still poorly understood. The over-expression of UPA has been detected in various malignancies including breast (Miyake et al., 1999), prostate (Yang et al., 2000), colon (Duggan et al., 1995), and pancreatic (Lee et al., 2003b). Some data have shown that a high level of uPA in tumors is associated with a rapid disease progression and a poor prognosis (Solomayer et al., 1997; Bouchetm et al., 1998). In addition, studies performed with both in vitro and in vivo experimental models have demonstrates that the levels of UPA are closely associated with the degree of tumor cell invasion (Xing et al., 1996). Blocking uPA expression or disruption of UPA binding to UPAR has been found to significantly inhibit tumor cell invasion and metastasis in various tumor models (Alonso et al., 1996; Kriiger et al., 2000). From these facts, it is apparent that UPA plays a key role in tumor progression and metastasis. We recently demonstrated a cellular mechanism for invasion-metastasis via hepatocyte growth factor/c-Met signaling in human gastric cells together with the induction of the urokinase proteolysis network.

The mitogen-activated protein kinases (MAPK) transduce extracellular signals into cellular responses, and so they play important roles in proliferation, apoptosis, differentiation, migration and cytoskeleton remodeling of cells (English et al., 1999; Widmann et al., 1999).

There are at least three distinct MAP kinase signal transduction pathways in mammalian cells that lead to activation of either the extracellular regulated kinases (ERKs); the C-Jun and N-terminal kinase/ stress-activated protein kinase (JNK/SAPK) pathway 
or the p38 MAPK pathway. Activated ERK subsequently transmits the mitogenic signal by phosphorylating the down stream target proteins such as the transcription factors, c-myc and c-jun, which control the expression of protein involved in growth (Lewis et al., 1998). On the other hand, the p38 signal transduction pathway also plays an essential role in regulating such cellular processes as inflammation, differentiation, cell growth, and death (Iwasaki et al., 1999).

In stomach cancer, expression of UPA/uPAR is essential for tumor cell invasion and metastasis. However, the mechanism that is responsible for uPA/ UPAR expression in cancer cells remains unclear. It has been previously shown that ERKs plays an important role in controlling pancreatic cancer cell growth. Inhibition of the MEK/ERK cascade blocks pancreatic cancer cell proliferation while the activation of this pathway by growth factors and cytokines is associated with the induction of pancreatic cancer growth and invasion (Douziech et al., 1999; Ehlers et al., 2000). In addition, some studies have demonstrated that p38 MAP kinase negatively regulates pancreatic cancer cell proliferation (Xian et al., 2001; Lee et al., 2003a). In contrast, the role of ERK and p38 MAPK in regulating stomach cancer cell proliferation is not understood.

In this study, we will now try to show the interaction between the MEK/ERK and p38 MAP kinase pathways in human gastric cancer cells concomitant with the induction of the urokinase proteolysis network.

\section{Materials and Methods}

\section{Cell culture}

We used two human gastric cancer cell lines in our experiments: the poorly differentiated adenocarcinoma, NUGC-3, and the moderately differentiated tubular adenocarcinoma, MKN-28. The cell lines were obtained from the Korea Cell Line Bank. These cells were maintained on plastic in Dulbecco's Modified Eagle's Medium (DMEM) supplemented with 10\% fetal bovine serum, $1 \mathrm{mM}$ sodium pyruvate, $0.1 \mathrm{mM}$ nonessential amino acids, $2 \mathrm{mM}$ L-glutamine, twofold vitamin solution, and $50 \mathrm{U} / \mathrm{ml}$ penicillin/streptomycin (Life Technologies Inc., Gaithersburg, MD). Unless otherwise noted, the cells were passaged and removed when they were $70-80 \%$ confluent.

\section{Western blot analysis}

Cells were seeded onto six-well plates $\left(1 \times 10^{6}\right.$ cells/well) and incubated in a $5 \% \mathrm{CO}_{2}$ incubator for $24 \mathrm{~h}$. The cells were then serum-starved for $24 \mathrm{~h}$ and treated with increasing concentrations or times of HGF. The cells were harvested, then lysed in a lysis buffer $(20 \mathrm{mM}$ Tris- $\mathrm{HCl}, 137 \mathrm{mM} \mathrm{NaCl}, 10 \%$ Glycerol, $1 \%$ Triton $\mathrm{X}-100,1 \mathrm{mM} \mathrm{Na} \mathrm{VO}_{4}$, and 1 $\mathrm{mM}$ PMSF) and centrifuged at $13,000 \times \mathrm{g}$ for $5 \mathrm{~min}$. The supernatants were transferred into new tubes and protein concentrations were determined using $\mathrm{BCA}$ protein assay reagent (Pierce Biotechnology Inc., Rockford, IL) using bovine serum albumin as a standard. The proteins $(100 \mu \mathrm{g})$ were separated in a $10 \%$ SDS-polyacryamide gel and then transferred onto nitrocellulose membranes, which were blotted with primary antibodies. Secondary antibodies conjugated with horseradish peroxidase were detected using chemiluminescence solution (KPL Inc., Gaithersburg, MD).

For uPA analysis, the cells $\left(1 \times 10^{6} /\right.$ well) were plated overnight in complete medium, starved for 24 $\mathrm{h}$, and then treated with 5,10 and $20 \mu \mathrm{M}$ MEK inhibitor (PD098059) or 1, 5 and $10 \mu \mathrm{M}$ p38 MAPK inhibitor (SB203580) for $1 \mathrm{~h}$ prior to incubation with $10 \mathrm{ng} / \mathrm{ml} \mathrm{HGF}$ for $48 \mathrm{~h}$. The UPA, secreted in media, was analysed by Western blotting using a rabbit polyclonal antibody against human uPA (389, American Diagnostica, Greenwich, CT).

\section{Gel zymography for uPA}

The cells were harvested. Equal amount of proteins were resolved under non-reducing condition in $10 \%$ SDS-polyarylamide gels impregnated with $0.4 \%$ casein and $15 \mathrm{mg} / \mathrm{ml}$ human plasminogen for uPA. After electrophoresis, the gels were washed for 2 $h$ in a solution of $50 \mathrm{mM}$ Tris- $\mathrm{HCl}(\mathrm{pH} \mathrm{7.5),2 \%}$ Trition $\mathrm{X}-100$ and $0.02 \% \mathrm{NaN}_{3}$, and then they were placed overnight in $150 \mathrm{mM} \mathrm{NaCl}$ and $100 \mathrm{mM}$ Tris solution. Following staining in a $0.2 \%$ Coomassie brilliant blue solution in methanol:acetic acid:water (4:1:5) and then destaining in a same solution without the dye, the enzyme activity was detected as the negatively stained regions. Zymographic analyses were performed in at least 3 independent experiments.

\section{Anchorage-dependent cell proliferation by cell counting}

The cells $(1,000 /$ well) were seeded in a 96-well plate in a medium supplemented with $5 \%$ FBS, and they were incubated for $24 \mathrm{~h}$. Cells were then serumstarved for $24 \mathrm{~h}$ and treated for $72 \mathrm{~h}$ with or without HGF $(10 \mathrm{ng} / \mathrm{ml})$ in the presence of 5,10 and 20 $\mu \mathrm{M}$ PD098059 and 1, 5 and $10 \mu \mathrm{M}$ SB203580. At the end of this incubation period, $50 \mu \mathrm{l}$ of $2 \mathrm{mg} / \mathrm{ml}$ 3-(4,5-dimethylthiazol-2-yl)-2,5-diphenyltetrazolium bromide (MTT) solution was added and the cells were allowed to incubate for $3 \mathrm{~h}$ at $37^{\circ} \mathrm{C}$. The supernatant was carefully removed by aspiration and convert dye was dissolved with $100 \mu \mathrm{l}$ DMSO. The 
plates were placed in a microplate shaker for $5 \mathrm{~min}$, and the absorbance was measured at $570 \mathrm{~nm}$ using a Biorad multiscan plate reader.

\section{Pre-treatment with PD098059 and SB203580}

The cells $\left(1 \times 10^{6} /\right.$ well $)$ were plated overnight in complete medium and then washed. The cells cultured in serum-free DMEM were pre-treated with $10 \mu \mathrm{M}$ PD098059 for $30 \mathrm{~min}$, and then they were treated or left untreated with $5 \mu \mathrm{M}$ SB203580 for $20 \mathrm{~min}$. The cell lysates were immunoblotted with a phospho-ERK antibody.

\section{Transient transfection}

The dominant negative (DN) MEK1 (S218A, S222A) expression vector was kindly gifted from Dr. S.M. Ahn (Korean National Institute of Health, Seoul, Korea). The DN-MEK1 vector was transfeced into
A
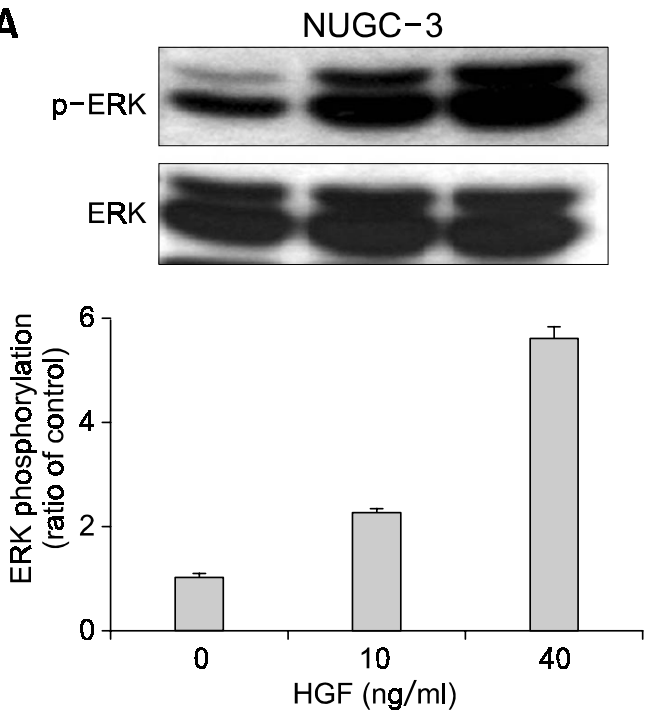

B
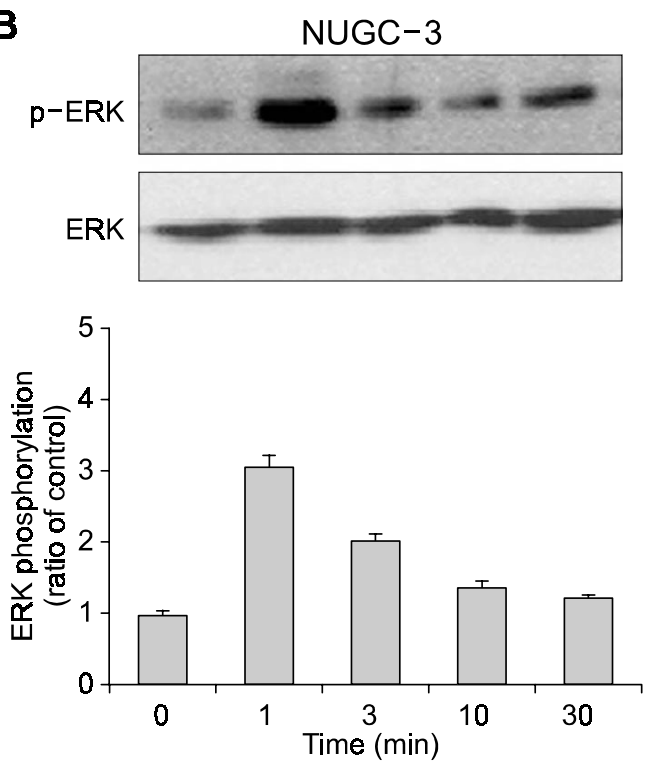
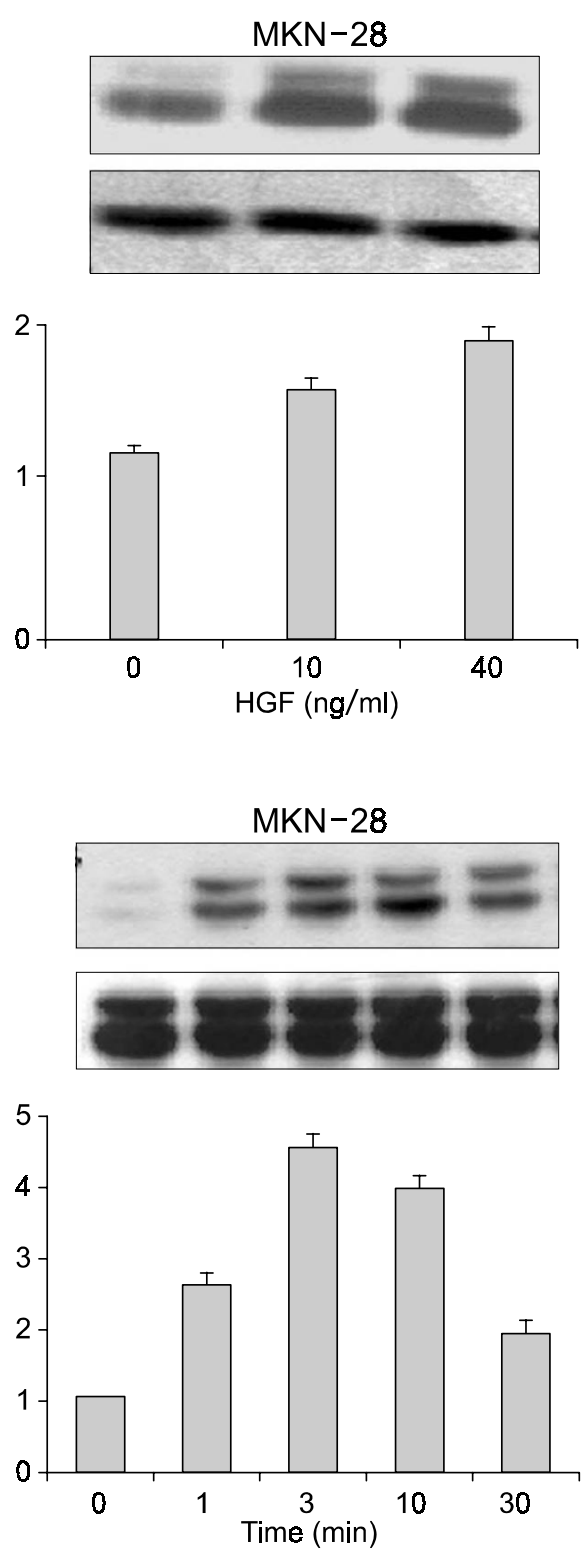

Figure 1. Effects of HGF on ERK activation. The cells were cultured in RPMI-10\% FBS, washed and then incubated for an additional $24 \mathrm{~h}$ in serum free medium. The cells were then stimulated for 15 min with 0,10 , or $40 \mathrm{ng} / \mathrm{ml}$ HGF (A) or for $0,1,3$, or 10, $30 \mathrm{~min}$ with $10 \mathrm{ng} / \mathrm{ml} \mathrm{HGF} \mathrm{(B).} \mathrm{Cell} \mathrm{lysates} \mathrm{were} \mathrm{prepared} \mathrm{and} \mathrm{proteins} \mathrm{were} \mathrm{resolved}$ on a $10 \%$ SDS-polyacrylamide gel under reducing condition. ERK1/2 activation was measured evaluated by Western blot analysis using ERK and phosphorylated ERK antibodies. Values are means \pm SD of triplicates of three independent experiments. 
NUGC3 cells using lipofectamine according to the manufacturer's protocol (Life Technologies Inc., Gaithersburg, MD). Cells were cultured in media containing $300 \mu \mathrm{g} / \mathrm{ml} \mathrm{G}-418$ for 2 weeks. The G-418 resistant cell clones were selected and the level of ERK protein was analyzed by Western blotting.

\section{Results}

\section{Activation of ERK and p38 kinase following treatment with HGF}

To elucidate the involvement of MAPK activity on the HGF-mediated UPA expression, we analyzed the
A

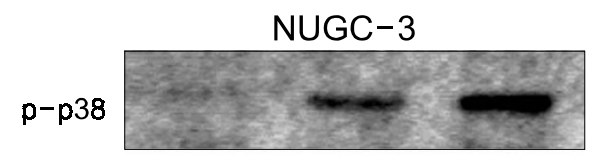

p38
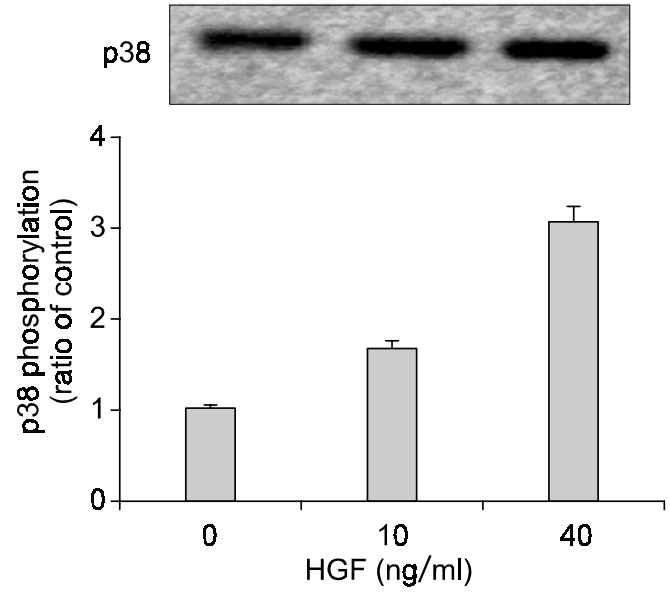

B
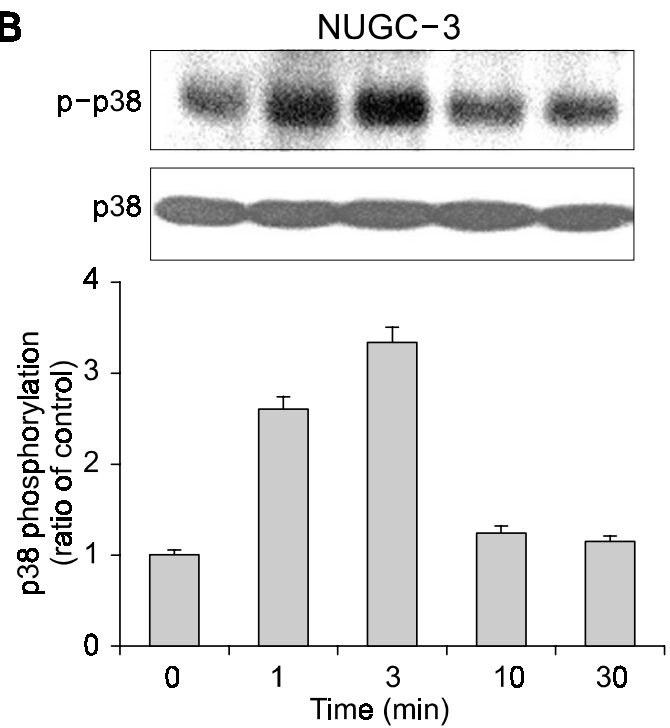
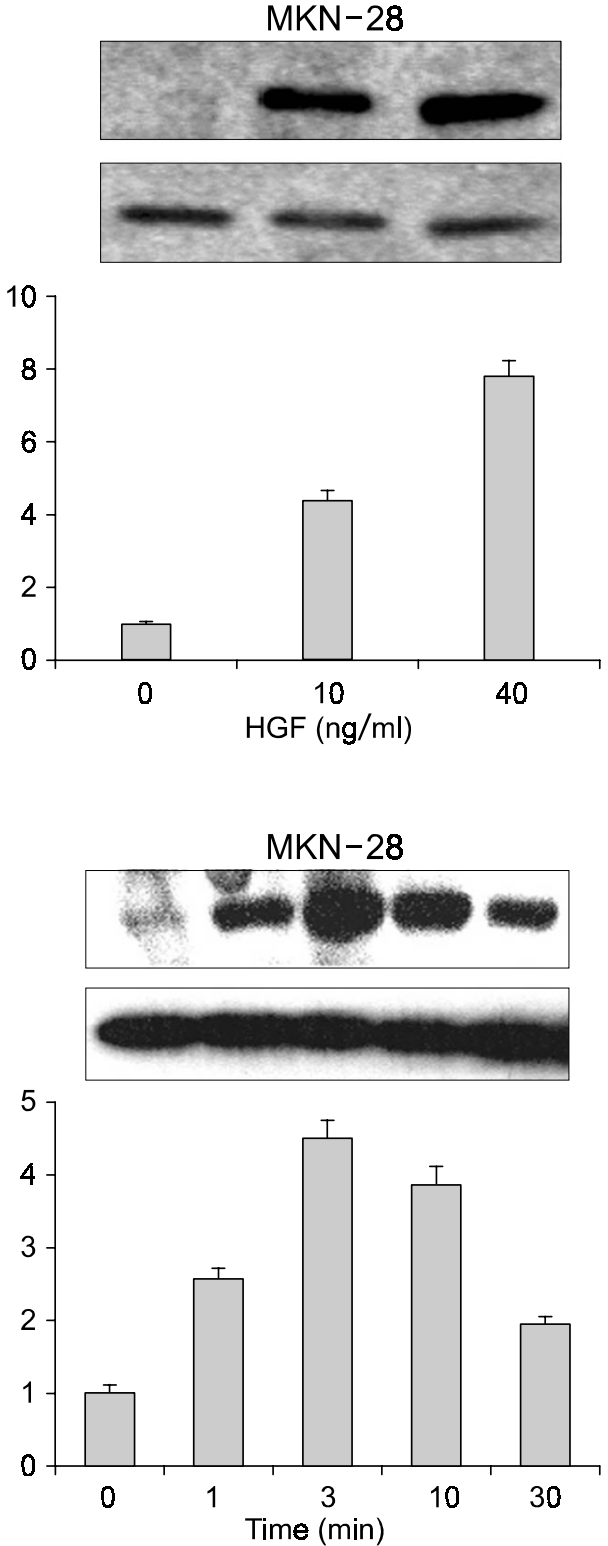

Figure 2. Effects of HGF on the phosphorylation of p38 kinase. The Cells were cultured in RPMI-10\% FBS and starved for $24 \mathrm{~h}$ in serum-free medium. The cells were then stimulated for 15 min with 10 and $40 \mathrm{ng} / \mathrm{ml} \mathrm{HGF}$. p38 activation was measured evaluated by Western blot analysis using p38 and phosphorylated p38 antibodies. Values are means $\pm S D$ of triplicates of three independent experiments. 
ERK and p38 phophorylation in the NUGC-3 cells, and the MKN-28 cell that had been treated with 0,10 or $40 \mathrm{ng} / \mathrm{ml}$ HGF. ERK phosphorylation was increased in the HGF-treated cells in a dose dependent manner (Figure $1 \mathrm{~A})$. The addition of $10 \mathrm{ng} / \mathrm{ml}$ HGF to both the serum starved cell lines rapidly stimulated the ERK phosphorylation. ERK activation occured within 1-3 min and it declined by 30 min (Figure 1B). p38 phosphorylation was also increased in both the HGF-treated cell lines in a dose dependent manner (Figure 2A). p38 activity simultaneously increased with ERK activity (Figure 2B).

NUGC-3

UPA
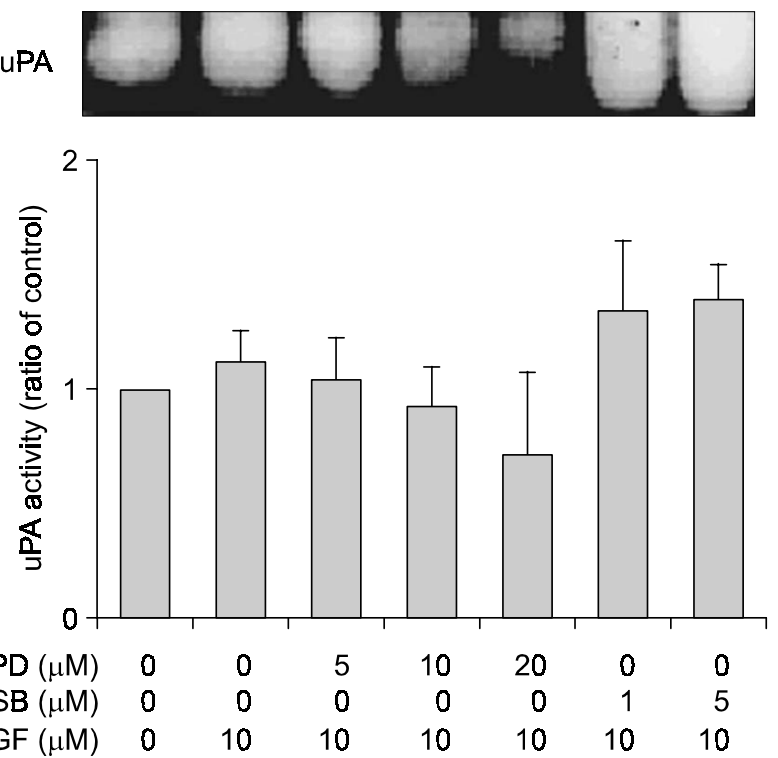
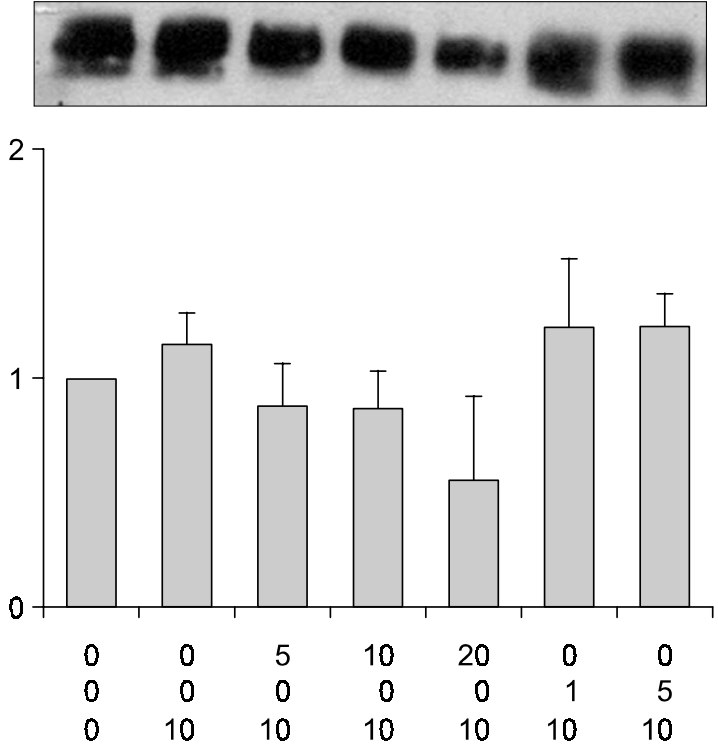

Figure 3. Effects of PD098059 and SB203580 on HGF-induced UPA expression in NUGC-3 cells. The cells were cultured in RPMI-10\% FBS and starved for $24 \mathrm{~h}$ in serum-free medium. Serum-starved cells were pre-treated with 5, 10, or $20 \mu \mathrm{M}$ PD098059 and 1 or $5 \mu \mathrm{M}$ SB203580 for $1 \mathrm{~h}$ and then treated with $10 \mathrm{ng} / \mathrm{ml}$ HGF for $48 \mathrm{~h}$. UPA expression in the supernatants was then analyzed by zymography (A) and Western blot analysis (B) under non-reducing conditions. Values are means $\pm S D$ of triplicates of three independent experiments.
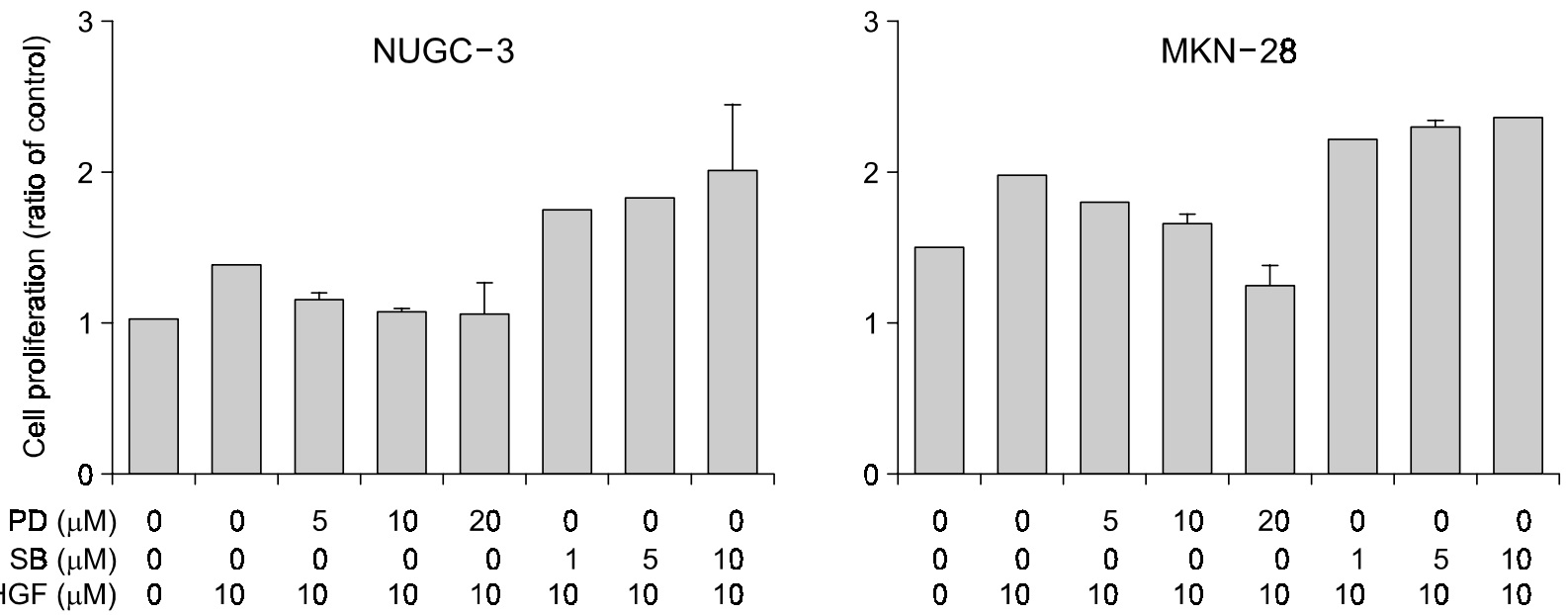

Figure 4. Effects of PD098059 and SB203580 on cell proliferation. Cells were plated in 96 well plates at a density of $1.5 \times 10^{3}$ cells/well and starved in serum-free medium for $24 \mathrm{~h}$. Cells were pre-treated with indicated concentrations of PD098059 or SB203580 for $72 \mathrm{~h}$ and then treated with $10 \mathrm{ng} / \mathrm{ml} \mathrm{HGF}$. Cell viability was measured by the MTT assay. Values are means \pm SD of triplicates of three independent experiments. 

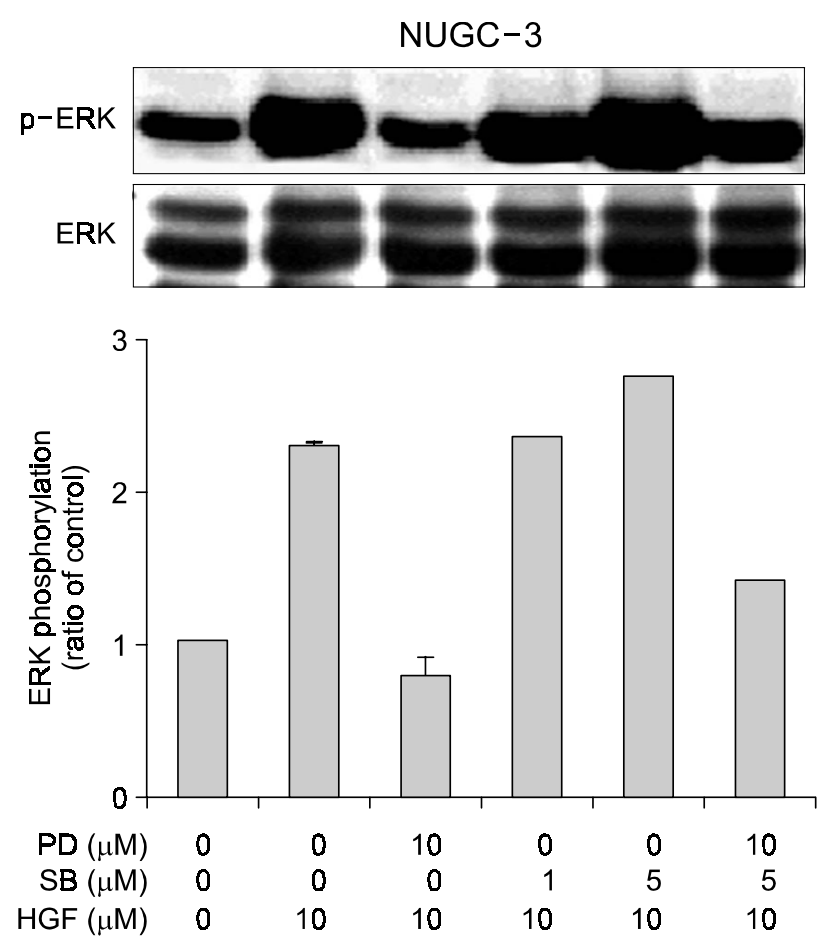
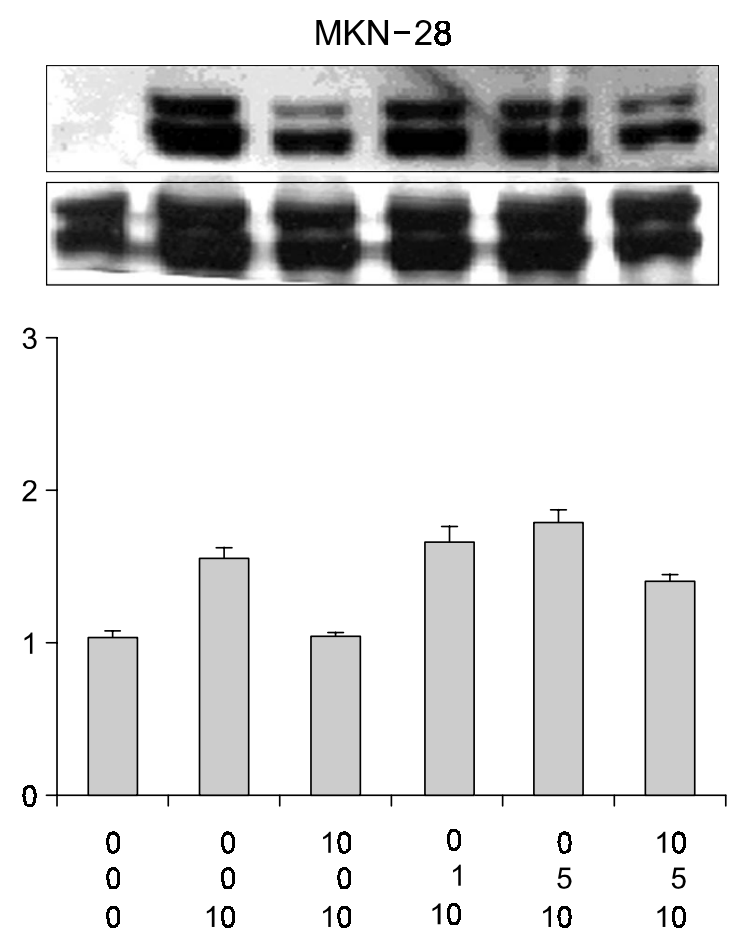

Figure 5. Effects of PD098059 and/or SB203580 on HGF-induced ERK phosphorylation. Serum-starved cells were pre-treated with 10 $\mu \mathrm{M}$ PD098059 and/or 1 and $5 \mu \mathrm{M} \mathrm{SB203580}$ for $30 \mathrm{~min}$ and then treated with $10 \mathrm{ng} / \mathrm{ml}$ HGF for $15 \mathrm{~min}$. ERK1/2 activation was measured by Western blot analysis using ERK and phosphorylated ERK antibodies. Values are means \pm SD of triplicates of three independent experiments.

\section{Effects of PD098059 and SB203580 on UPA secretion}

To test whether ERK activation and p38 activations were involved in the HGF-mediated UPA secretion, the cells were pre-treated with PD098059 or SB203580, and the uPA secretion was measured by Western blotting and gel zymography. The NUGC-3 cells showed that HGF-mediated UPA secretion was reduced with the increasing concentrations of PD098059. Densitometric analysis indicated that 20 $\mu \mathrm{M}$ of the MEK1 inhibitor reduced the urokinase secretion by $40-50 \%$. In contrast, pre-treatment with SB203580 increased the UPA secretion and activity. These results suggested that HGF-mediated UPA secretion and the augmentation of this activity were regulated by ERK and p38 activation (Figure 3).

\section{Effects of PD098058 and SB203580 on cell proliferation}

To determine whether MAP kinase plays a role in cell proliferation, MTT assay was performed after treatment of the cells with ERK, PD098058 and SB203580. Following $72 \mathrm{~h}$ treatment, PD098058 significantly blocked cell proliferation in a dosedependent manner. In contrast, SB203580 had an effect on cell proliferation (Figure 4).

\section{Effects of PD098059 and/or SB203580 on HGF-induced ERK1/2 phosphorylation}

To investigate the possibility of interaction between the ERK and the p38 activations in the HGF-mediated UPA expression, the effects of SB203580 on ERK activation were measured. Pre-treatment of SB203580 increased ERK phosphorylation in the HGF-treated cells. A co-treatment of PD098058 and SB203580 decreased the ERK phosphorylation. These results suggested that the HGF-mediated UPA secretion and the augmentation of this activity were regulated by ERK activation, and p38 activation might indirectly affect HGF-mediated uPA secretion. In other words, the increments of HGF-mediated UPA secretion and its level of expression according to the treatment by SB203580 were mediated through the ERK activation (Figure 3 and 5).

\section{Effects on a dominant negative-MEK1 gene on UPA expression}

We transfected the dominant negative-MEK1 gene to NUGC-3 cells and measured the HGF-mediated UPA secretion. Transfection of DN-MEK1 caused a decrease in UPA secretion after stimulating with HGF, suggesting that the HGF-mediated UPA secretion was regulated by the ERK activation (Figure 6). 
A
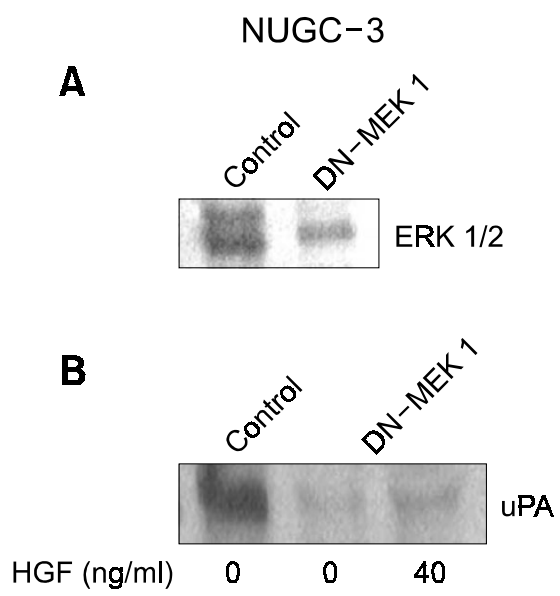

Figure 6. Effect of dominant-negative (DN) MEK1 on HGF-induced UPA expression in NUGC-3 cells. The DN-MEK1 was transfected into NUGC3 cells using lipofectamine and selected stable DN-MEK1 cells. ERK protein level was confirmed by Western blotting using an ERK antibody and equal loading of proteins was confirmed by a GAPDH antibody (A). Vector-transfeced (control) cells and DN-MEK1 cells were starved for $24 \mathrm{~h}$ in serum-free medium and treated with HGF for 48 $h$. The uPA protein levels in the supernatants were then analyzed by Western blotting under non-reducing conditions (B).

\section{Discussion}

An increased expression of UPA has been associated with tumor invasiveness and metastasis. In addition, binding of UPA to its receptor can stimulate epithelial cell motility by a mechanism that is independent of proteolysis (Juan et al., 2001). UPA expression can be regulated by growth factors that bind to tyrosine kinase receptors and this activates the Ras signaling pathway (Aguirre-Guiso et al., 1999). This pathway involves the activation of MAPK by c-Raf, which in turn activates the extracellular signal regulated kinase (ERK).

Some studies have reported that hepatocyte growth factor and transforming growth factor- $\beta_{1}$ (TGF- $\beta_{1}$ ) stimulate the migration and invasiveness of transformed epithelial cells concomitantly with the up-regulation of uPA (Restuccia et al., 2000; Lee et al., 2003b). HGF's direct effects on cells for stimulating malignancy and for signaling through the HGF receptors very likely require c-Met. In a separate study, we have shown that HGF/c-Met signaling enhanced stomach cancer cell proliferation and it increased UPA synthesis and its activity. Inhibition of UPA receptors by a monoclonal antibody against the UPA receptor decreased tumor cell invasion.

The intracellular down stream signal for HGF/cMet is still poorly understood, and several pathways might be involved. Transformed keratinocytes respond to TGF- $\beta$ by their stimulated cell motility and invasiveness together with enhancement of the UPA expression/secretion. Depletion of ERK protein by a treatment with antisense oligonucleotides reduced the basal UPA production and abolished any stimulation of UPA secretion and cell motility by TGF- $\beta$. We also demonstrated reduction of uPA production in NUGC-3 cell line transfected with DN-MEK1 gene. PD098059 decreased the TGF- $\beta$ stimulated cell motility and invasiveness. These data suggest that the Ras/MAPK transduction pathway is involved in the invasive response of transformed keratinocytes to TGF- $\beta$ (Matsumoto et al., 1994). HGF also needs to cooperate with a ras oncogene for the progression of tumor cells to the invasive phenotype. The physiological role of ERKs for stimulating cell proliferation has been well documented. Constitutionally active MEK mutants and the elevated expression of MAP kinase have been reported to induce malignant transformation in adenocarcinoma and also in other cell types (Greulich et al., 1998; Blalock et al., 2000). ERK1/2 and p38 kinase act as critical downstream pathways that mediate the progression of stomach cancer cells. However, the specific downstream effects and physiological interactions of these proteins in stomach cancer cells are not fully understood. Our previous study showed that ERK and p38 kinase are involved in the HGFmediated uPA expression in pancreatic cancer cell line, L3.6PL and IMIM-PC2.

Thus, we examined the role of the MAP kinase signaling pathway on the stimulation of UPA synthesis in stomach cancer cells by using HGF. This study showed that the phosphorylation of ERK and the p38 kinase are dependent on the dosage of HGF. We also showed that UPA secretion and zymoactivity in the NUGC-3 cell lines were stimulated with HGF, which suggests the involvement of ERK and p38 kinase in the HGF-mediated UPA expression.

The effects of PD098059 and SB203580 were measured in order to clarify which signaling pathway, between the ERK and p38 kinase pathways, might play the more important role in HGF-induced UPA secretion in the stomach cancer cell lines. While a pre-treatment with PD098059 reduced the UPA secretion, pre-treatment with SB203580 increased the UPA secretion. Increments of HGF-mediated UPA expression via SB203580 pre-treatment were also shown to be mediated by ERK activation. It is likely that a blockade on the ERK pathway affects the expression of multiple genes that are involved in the invasive process (Garbisa et al., 1992; Crawford et al., 1994; Matsumoto et al., 1994). To determine whether ERK and p38 Map kinases play a role in cell proliferation, pre-treatment with PD098059 or SB203580 was done. SB203580 promoted proliferation of both cell lines in a concentration-dependent manner, but this proliferation was decrea- 
sed by PD098059. Xian et al., also reported similar results in the PCNC-1 pancreatic cancer cell line. They showed that SB203580 significantly enhances cell proliferation as measured by both thymidine incorporation and the cell number, indicating that p38 kinase functions as a negative growth regulator in the PANC-1 pancreatic cells. Further more, following a treatment with SB203580, more cells were remained in the $S$ phase while there was a decrease of the number of cells in the G0/G1 phase, further supporting the importance of p38 MAP kinase as a negative regulator of PANC-1 cell proliferation (Xian et al., 2001).

Based on this evidence, we have demonstrated that ERK and p38 MAP kinase are concurrently phosphorylated and activated in the NUGC-3 and MKN-28 stomach cancer cell lines that were first stimulated with HGF. Indeed, there is interaction between the p38 kinase and ERK pathways. This interaction was found to regulate UPA production in the carcinoma cells. The p38 kinase is a negative regulator for the ERK signaling pathway and hence, it negatively regulates stomach cancer cell proliferation and invasiveness. These findings raise the exciting possibility that PD98059 may be a clinical target for reducing the invasiveness of those tumors in which the signaling cascade is constitutively activated. In the future, we will perform studies aimed a evaluating the involvement of stress-activated MAPKs on stomach cancer cells' response to HGF.

\section{Acknowledgement}

This work was supported by a grant from the Yeungnam University Foundation 2004 (205-A-236009).

\section{References}

Alonso DF, Farias EF, Ladeda V, Davel L, Puricelli L, Bal de Kier Joffe E. Effects of synthetic urokinase inhibitors on local invasion and metastasis in a murine mammary tumor model. Breast Cancer Res Treat 1996;40:209-23

Aguirre-Guiso JA, Alonso DF, Farias EF, Gomez DE, de Kier Joffe EB. Dysregulation of the signaling pathways controlling urokinase production. Its relationship with the invasive phenotype. Eur J Biochem 1999;263:295-304

Blalock WL, Pearce M, Steelman LS. A conditionally-active form of MEK1 results in autocrine transformation of human and mouse hematopoietic cells. Oncogene 2000;27;19:52636

Bouchetm C, Spyratos F, Hacene K, Furcos L, Becette V, Oglobine J. Prognostic value of urokinase plasminogen activator in primary breast carcinoma: comparison of two immunoassay methods. $\mathrm{Br} \mathrm{J}$ Cancer 1998;77:1495-501

Crawford HC, Matrisian LM. Tumor and stromal expression of matrix metalloproteinases and their role in tumor progression. Invasion Metastasis 1994;14:234-45

Douziech N, Calvo E, Laine J, Morisset J. Activation of MAP kinases in growth responsive pancreatic cancer cells. Cell Signal 1999;11:591-602

Duggan C, Maguire T, McDermott E, O'Higgins N, Fennelly $\mathrm{JJ}$, Duffy MJ. Urokinase plasminogen activator and urokinase plasminogen activator receptor in breast cancer. Int $\mathrm{J}$ Cancer 1995;61:597-600

Ehlers RA, Zhang Y, Hellmich MR, Evers BM. Neurotensinmediated activation of MAPK pathways and AP-1 binding in the human pancreatic cancer cell line, MIA PaCa-2. Biochem Biophys Res Commun 2000;269:704

English J, Pearson G, Wilsbacher J, Swantek J, Karandikar $\mathrm{M}, \mathrm{Xu} \mathrm{S}$, Cobb MH. New insights into the control of MAP kinase pathways. Exp Cell Res 1999;253:255-70

Garbisa S, Scagliotti G, Di Francesco C, Caenazzo C, Onisto M, Micela M, Stetler-Stevenson WG, Liotta L. Correlation of serum metalloproteinase levels with lung cancer metastasis and response to therapy. Cancer Res 1992;52:4548-9

Greulich H, Erikson RL. An analysis of MEK1 signaling in cell proliferation and transformation. J Biol Chem 1998;273: 13280-8

Iwasaki S, Iguchi M, Watanabe $\mathrm{K}$, Hoshino R, Tsujimoto M, Kohno M. Specific activation of the p38 mitogen-activated protein kinase signaling pathway and induction of neurite outgrowth in PC12 cells by bone morphogenetic protein-2. J Biol Chem 1999;274:26503-10

Juan FS, Maite I, Pilar F, Jorge M, Miguel Q. Involvement of the Ras/MAPK signaling pathway in the modulation of urokinase production and cellular invasiveness by transforming growth factor-b1 in transformed keratinocytes. Biochem Biophy Res Commun 2001;273:521-7

Korczak B, Kerbel RS, Dennis JW. Autocrine and paracrine regulation of tissue inhibitor of metalloproteinases, transin, and urokinase gene expression in metastatic and non-metastatic mammary carcinoma cells. Cell Growth Differ 1991;2: $335-41$

Kriiger A, Soeltl R, Lutz V, Wilhelm OG, Magdolen V, Rojo EE, Hantzopoulos PA, Graeff H, Gansvacher B, Schmitt M. Reduction of breast carcinoma tumor growth and lung colonization by overexpression of the soluble urokinase-type plasminogen activator receptor (CD87). Cancer Gene Ther 2000;7:292-9

Lee KH, Hyun MS, Kim JY. Growth factor-dependent activation of the MAPK pathway in human pancretic cancer: MEK/ERK and p38 MAP kinase interaction in uPA synthesis. Clin Exp Meta 2003a;20:499-505

Lee KH, Hyun MS, Kim JY. Invasion-Metastasis by $\mathrm{He}$ patocyte Growth Factor/c-Met Signaling Concomitant with Induction of Urokinase plasminogen Activator in Human Pancreatic Cancer: Role as Therapeutic Target. Cancer Research Treatment 2003b;35:207-12

Lewis TS, Shapiro PS, Ahn NG. Signal transduction through MAP kinase cascades. Adv Cancer Res 1998;74:49-139

Matsumoto K, Nakamura T, Kramer RH. Hepatocyte growth 
factor/scatter factor induces tyrosine phosphorylation of focal adhesion kinase (p125FAK) and promotes migration and invasion by oral squamous cell carcinoma cells. J Biol Chem 1994;69:31807-13

Miyake H, Hara L, Yamanaka K, Arakawa S, Kamidono S. Elevation of urokinase-type plasminogen activator and its receptor densities as new predictors of disease progression and prognosis in men with prostate cancer. Int J Oncol 1999; 14:35-41

Restuccia C, Angelucci A,Gravina GL,Villanova I, Teti A, Albini A, Bologna M. Osteoblast-derived TGF-beta1 modulates matrix degrading protease expression and activity in prostate cancer cells. Int J Cancer 2000;85:407-15

Solomayer EF, Kiel IJ, Wallwiener D, Bode S, Meyberg G, Sillem M, Gollan CH, Kramer MD, Krainick U, Bastert G. Prognostic relevance of urokinase plasminogen activator detection in micrometastatic cells in the bone marrow of patients with primary breast cancer. $\mathrm{Br} \mathrm{J}$ Cancer 1997;76:812-8
Widmann C, Gibson S, Harpe MB, Johnson GL. Mitogen-activated protein kinase: conservation of a three-kinase module from yeast to human. Physiol Rev 1999;79:143-80

Xian ZD, Thomas EA. MEK/ERK-mediated proliferation is negatively regulated by P38 MAP kinase in the hman pancreatic cancer cell line, PANC-1. Biochem Biophy Res Commun 2001;282:447-53

Xing RH, Rabbani SA. Overexpression of urokinase receptor in breast cancer cells results in increased tumor invasion, growth and metastasis. Int J Cancer 1996;67:423-9

Yang JL, Seetoo DG, Wang Y, Ranson M, Berney CR, Ham JM, Russell PJ, Crowe PJ. Urokinase-type plasminogen activator and its receptor in colorectal cancer: independent prognostic factors of metastasis and cancer-specific survival and potential therapeutic targets. Int J Cancer 2000;20:431-9 